\title{
Grocery games: How ethnically diverse low-income mothers support children's reading and mathematics
}

\author{
Diana Leyva $^{\mathrm{a}, *}$, Catherine S. Tamis-LeMonda ${ }^{\mathrm{b}}$, Hirokazu Yoshikawa $^{\mathrm{b}}$, \\ Carmen Jimenez-Robbins $^{\text {b }}$, Lauren Malachowski ${ }^{a}$ \\ a Davidson College, United States \\ ${ }^{\mathrm{b}}$ New York University, United States
}

\section{A R T I C L E I N F O}

\section{Article history:}

Received 20 April 2016

Received in revised form

11 November 2016

Accepted 4 January 2017

\section{Keywords:}

Literacy

Home environment

Cross-cultural

Academic achievement

School transition

\begin{abstract}
A B S T R A C T
Parent-child interactions are an important source of variability in children's learning. We asked: (1) to what extent do low-income and ethnically diverse mothers engage in maternal writing support, math support, and directiveness in a grocery shopping game; (2) do these maternal behaviors predict gains in children's reading and mathematics from age 5 (T1) to first grade (T2), and (3) what role do ethnicity and children's baseline skills (T1) play in these associations. Participants were 212 low-income African American, Dominican, Mexican, and Chinese mothers and their 5-year-old children. Maternal writing support predicted gains in children's reading skills but math support did not predict gains in children's mathematics. Maternal directiveness negatively predicted gains in both children's reading and mathematics. Ethnicity and children's baseline skills did not moderate these associations. Implications for family-focused interventions serving low-income and ethnically diverse populations are discussed.
\end{abstract}

(c) 2017 Elsevier Inc. All rights reserved.
The way that parents interact with children during literacy and math activities is a key contributor to individual differences in children's reading and mathematics achievement (Morrison \& Cooney, 2001). Understanding this source of variability across families of different ethnic backgrounds is important because children's early reading and mathematic skills are strong predictors of later school achievement (Duncan et al., 2007), and early income-based and racial/ethnic disparities in reading and mathematics tend to persist beyond early childhood and into adolescence (Duncan \& Murnane, 2014). Here we examined whether three aspects of parent-child interactions - maternal writing support, math support, and directiveness - predicted gains in children's reading and mathematics from age 5 (T1) to first grade (T2) across four ethnic and immigrantorigin groups: African American, Dominican, Mexican, and Chinese.

We chose to study these ethnic groups based on their substantial representation among families living in poverty in the United States (U.S. Census Bureau, 2015) and because economic pressure and poverty-related stressors may affect the ability of these families to interact in supportive and warm ways with their children (Yoshikawa, Aber, \& Beardslee, 2012). Furthermore,

\footnotetext{
* Corresponding author at: Psychology Department, Davidson College, $405 \mathrm{~N}$. Main St. Box 7136, Davidson, NC 28035, United States.

E-mail address: dileyva@davidson.edu (D. Leyva).
}

African American and Latino children are disproportionately represented among those with low school achievement and high rates of school dropout (U.S. Department of Education, National Center for Education Statistics, 2015). Hence, studying maternal writing support, math support, and directiveness in these ethnic and immigrant-origin groups may provide specific information about which parenting practices support children's learning under challenging economic circumstances in an increasingly diverse society.

\section{The development of children's reading and mathematics skills}

Before the onset of formal schooling, children develop foundational literacy skills (Teale \& Sulzby, 1986). While some of these literacy skills are associated primarily with mastering written language, such as decoding (i.e., identifying the name of letters and words), other skills are associated primarily with oral language such as vocabulary and narrative construction, and yet others are meta-linguistics skills (e.g., phonological awareness). There is substantial evidence that written and oral language skills enhance each other and develop in mutual interaction (e.g., Dickinson, McCabe, Anastasopoulos, Peisner-Feinberg, \& Poe, 2003; Sénéchal, LeFevre, Smith-Chant, \& Colton, 2001). For example, children who read often develop large vocabularies. In turn, children with relatively larger vocabularies are better able to understand written text, and there- 
fore, have better reading comprehension skills than those with relatively smaller vocabularies. In this study, we focused on three of these literacy skills: decoding, reading comprehension, and vocabulary.

Before the onset of formal schooling, children also develop foundational math skills. Traditionally, these skills have been characterized as: a) procedural knowledge: strategies, rules and algorithms for completing a task (e.g., number calculations such as adding and subtracting); and b) conceptual knowledge: knowledge about mathematical principles and generalizations (e.g., math concepts such as number series; Baroody, Feil, \& Johnson, 2007). Procedural and conceptual knowledge about mathematics are intertwined; conceptual knowledge can aid appropriate and efficient use of skills (procedural knowledge), and vice versa (Baroody, Lai, \& Mix, 2006). In this study, we focused on number calculations and math concepts.

\section{Reading and mathematics in the context of grocery shopping}

Children's participation in ongoing cultural routines is central to developing key cognitive abilities (Rogoff, 2003; Vygotsky, 1978). Informal, every day activities, such as cooking and grocery shopping, are unique opportunities for adults to promote, challenge, and extend reading and mathematics abilities in children (Song \& Ginsburg, 1987; Vandermaas-Peeler \& Pittard, 2014). We focused on grocery shopping because it is a fairly universal food routine for families from different ethnic backgrounds living in urban settings, and also because children are aware of and eager to be part of this routine from very early on (Spagnola \& Fiese, 2007). Children can learn and practice a substantial amount of reading and mathematics in the context of grocery shopping; for example, reading labels and prices, counting, adding and subtracting numbers of food items, writing and checking a shopping list, and staying within a specific budget. Thus, we investigated maternal writing support, math support, and directiveness in the context of a grocery shopping game, in which parents and children made a grocery list and shopped at a pretend store.

\section{Maternal writing support}

Three common activities through which parents support the development of children's reading abilities at home are: reading books, talking about past events, and engaging in joint writing tasks (for a review see Reese, Sparks, \& Leyva, 2010). In this study, we focus on mothers' spontaneous strategies in making and using a grocery list, a joint writing task. We chose a joint writing task because it is a great way to develop foundational reading skills in children, including: a) word recognition skills, such as decoding, phonological awareness and sight recognition; and b) language comprehension skills, such as vocabulary, background and literacy knowledge, and verbal reasoning (Aram \& Levin, 2004; Bindman et al., 2014; Leyva, Reese, \& Wiser, 2012; Skibbe, Bindman, Hindman, Aram, \& Morrison, 2013).

Middle-class European American parents who report engaging in high levels of explicit teaching about writing and reading words at home have children with advanced decoding and spelling skills in kindergarten and first grade (Sénéchal, LeFevre, Thomas, \& Daley, 1998), as well as advanced reading achievement in third grade (Sénéchal \& LeFevre, 2002). One important type of writingsupport strategy that parents spontaneously engage in with their children (3-6 years) is breaking a word into units of sounds and linking each unit of sound to its corresponding letter. This type of parental writing support when children were 5- to 6-year-olds was concurrently associated with advanced decoding and phonological awareness (Aram \& Levin, 2001) and predicted reading comprehension and spelling when children were in second grade, in a study of low-income Israeli families (Aram \& Levin, 2004).

In subsequent studies conducted in the United States with primarily middle-class European American parents and their 3-5year-old children (Bindman et al., 2014; Skibbe et al., 2013), parental writing support was concurrently associated with children's decoding (Bindman et al., 2014) and predicted children's decoding and phonological awareness one year later (Skibbe et al., 2013). In another study with middle-income Hong Kong Chinese mothers and their 4- to 7-year-old children, a similar type of writing support was also related to advanced decoding (Lin et al., 2009).

Dictating and sounding out letters is an even more common writing-support strategy that middle-class European American parents naturally engage in with their 3- to 5-year-olds during joint writing tasks (Bindman et al., 2014; Burns \& Casbergue, 1992; Skibbe et al., 2013). This strategy is pervasive in communities that speak languages that have opaque orthography, such as English, because the rules of sound-letter correspondence are typically irregular. Consequently, breaking the word into units of sound is not always the most efficient strategy to teach children how to spell a word.

In this study, we focused on parents' efforts to highlight individual letters and sounds by dictating and sounding out letters or by breaking a word into units of sounds and linking each unit of sound to its corresponding letter. This type of writing support is consistently associated with children's decoding, reading comprehension, spelling, and phonological awareness across a range of communities as described above.

To date, no study has examined parental writing support in lowincome or ethnically diverse families in the United States. Hence, it is unclear whether parents in these communities engage in writing support in everyday activities at home, and if so, whether parental writing support predicts children's reading achievement. It is important to study low-income and ethnically diverse families to shed light on the different paths parents take in helping their children develop academic skills. Research into variation among parents in their support of academic skills can deepen our understanding of how young children acquire critical reading and mathematics abilities and how such abilities can be facilitated. One factor that may influence the association between parental writing support and reading achievement is the child's skill level. Children with less sophisticated reading skills might benefit more from parental writing support than children with more sophisticated reading skills (Aram, 2007; DeBaryshe, Buell, \& Binder, 1996). In fact, recent studies show that the effectiveness of reading instruction programs depends on whether the programs adapt the content and instructional activities to the child's entering skill level (Connor, Morrison, \& Katch, 2004). It is thus relevant to determine the moderating role of child skill levels on the association between parental writing support and children's reading achievement.

\section{Maternal math support}

Common activities through which parents support their children's development of mathematics are playing board games, reading number and shape books, singing number songs, discussing everyday number-related artifacts such as money, calendars and clocks, and engaging with their children in everyday numberrelated activities such as cooking and shopping. Parents of diverse socioeconomic status (SES) and ethnic backgrounds who report frequently engaging in these number-related activities at home across preschool, kindergarten, first and second grades have children with advanced math performance including number calculation and math concepts such as ordinality, cardinality, equivalence, and 
numerical magnitude (LeFevre et al., 2009; Manolitsis, Georgiou, \& Tziraki, 2013; Ramani, Rowe, Eason, \& Leech, 2015).

Counting is one of the earliest and most pervasive math-support strategies that working- and middle-class European American parents report using with their children at home (Blevins-Knabe \& Musun-Miller, 1996; Durkin, Shire, Riem, Crowther, \& Rutter, 1986; Saxe, Guberman, \& Gearhart, 1987). Direct observation of parentchild interactions in number-related activities has confirmed that counting is one of the most frequent math-support strategy used by middle-class parents from different ethnic backgrounds with their 3- to 4-year-old children (Anderson, 1997; Benigno \& Ellis, 2004; Vandermaas-Peeler, Ferretti, \& Loving, 2012).

In the context of cooking, an activity that involves but does not explicitly target mathematics, middle-class European American parents who were explicitly instructed to include numeracy guidance while cooking with their 4-year-old children engaged in significantly more counting, addition and subtraction than did parents who were not given any particular instruction. In turn, their children provided significantly more correct counting, addition, and subtraction responses than did children whose parents received no instruction during the cooking activity. However, there were no associations between this type of math support and children's concurrent performance on a standardized math test (Vandermaas-Peeler et al., 2012). In a subsequent study with low-income and ethnically diverse parents and their 5-year-old children, parental math support while playing a board game and engaging in a more structured math activity was not related to children's mathematics achievement. However, parental reports of math activities at home predicted mathematics achievement in this sample (Vandermaas-Peeler \& Pittard, 2014).

Taken together, the evidence on parent support of children's mathematics is mixed. Parental reports of math activities at home are consistently related to children's mathematics achievement (LeFevre et al., 2009, 2010; Manolitsis et al., 2013; Ramani et al., 2015). However, further research is needed to understand whether specific parental math-support strategies observed during parent-child interactions are indeed related to children's mathematics achievement (Bjorklund, Hubertz, \& Reubens, 2004; Skwarchuk, 2009; Vandermaas-Peeler et al., 2012; VandermaasPeeler \& Pittard, 2014).

In this study, we focused on the most documented math-support strategies that parents spontaneously use in everyday activities: counting, adding, and subtracting numbers (Benigno \& Ellis, 2004; Bjorklund et al., 2004; Skwarchuk, 2009; Vandermaas-Peeler et al., 2012; Vandermaas-Peeler \& Pittard, 2014). These strategies are crucial to numerical development because they teach children important properties of whole numbers, including numbers being countable, having unique successors, and increasing with addition and decreasing with subtraction (Siegler, Thompson, \& Schneider, 2011).

To our knowledge, only one study exists on observed parents' counting and calculating strategies in low-income and ethnically diverse families in the United States, and the sample size was fairly small ( $n=18$; Vandermaas-Peeler \& Pittard, 2014). Hence, there is a clear need to examine whether low-income and ethnically diverse parents in the United States engage in math-support strategies, and if so, whether parental math support predicts children's mathematics achievement. As with writing support, child skill levels might influence the relation between parental math support and mathematics. Children who have less advanced math knowledge may benefit more from parental math support than children who already have this knowledge (Benigno \& Ellis, 2004; Bjorklund et al., 2004; Saxe et al., 1987; Skwarchuk, 2009). Hence it is important to investigate the moderating role of child skill levels on the association between parental math support and children's mathematics.

\section{Maternal directiveness}

Teaching and learning complex skills such as reading and mathematics requires a great deal of persistence and effort on the part of both the parent and the child. Therefore, we were interested in examining the relation between parents' directiveness during the grocery shopping game and children's reading and mathematics. Directiveness is one type of control, an important behavioral dimension of parent-child interactions (Maccoby \& Martin, 1983; Morrison, Bachman, \& Connor, 2008) and is typically operationalized as parents' behaviors that take over or stop the child's activity (Carlson \& Harwood, 2003; Ispa et al., 2004). Others have referred to this type of control as intrusiveness; we refrain from using this term because this type of parental control is not 'universally' intrusive, interfering or insensitive (Carlson \& Harwood, 2003). Based on prior work, we operationalize directiveness as the mother taking over the child's activity during the grocery shopping game, thereby offering little autonomy to the child.

In joint writing tasks, middle-class European American parents who helped their 3- to 5-year-old child write independently, rather than taking over and writing for the child, had children with more advanced decoding one year later (Skibbe et al., 2013). In low-income Israeli families, parents who helped their 5-yearold children write independently, rather than taking over and writing for them, had children with more advanced decoding and word writing skills (Aram \& Levin, 2001). To our knowledge, only one study has examined parental directiveness in numberrelated tasks; however, the authors did not specifically investigate whether directiveness predicted children's mathematics achievement (Huntsinger, Jose, Larson, Balsink Krieg, \& Shaligram, 2000). In other teaching tasks, European American mothers from diverse socioeconomic backgrounds who took over a puzzle and solved it for the child when the child was 6-years-old had children with lower vocabulary scores and lower teacher ratings of academic competence at ages 6 and 8 (Culp, Hubbs-Tait, Culp, \& Starost, 2001; Olson, Bates, \& Kaskie, 1992). In a study with families from diverse socioeconomic and ethnic backgrounds, mothers who took over an origami-folding task and solved it for their pre-kindergarten children had children with lower vocabulary scores in a standardized test one year later (Hubbs-Tait, Culp, Culp, \& Miller, 2002). There is also evidence that low maternal directiveness while primary school children do math, reading and other homework is positively associated with amount of homework completed, standardized test scores, and class grades in a sample of primarily White and economically disadvantaged families in the United States (Cooper, Lindsay, \& Nye, 2000).

One factor that may influence the association between maternal directiveness and children's outcomes is ethnicity (Ispa et al., 2004). Typically, in European American samples maternal directiveness is negatively associated with child outcomes; perhaps children experience control as stressful due to the European American endorsement of independence, autonomy, and the egalitarian parent-child relationships (Ispa et al., 2004). In contrast, maternal directiveness is either positively related or unrelated to child outcomes in African American, Chinese, Chinese American, and Latino samples (Brody \& Flor, 1988; Chao, 2001; Carlson \& Harwood, 2003; Gibson-Davis \& Gassman-Pines, 2010; Keels, 2009; Lindahl \& Malik, 1999; McAdoo, 2002). In these contexts, children may experience mothers' attempts to control the interaction as demonstrations of involvement and a legitimate concern for the child's well-being, given the strong values of interdependence and social cohesion and hierarchical parent-child relationships embraced by these communities.

Children's level of skills is another factor that may moderate associations between maternal directiveness and children's academic skills and performance. To date, the evidence is somewhat 
mixed. Elementary school children with initial low skill levels seem to benefit more from maternal directiveness than children with initial high skill levels. Specifically, when children perform poorly and are uncertain about how to meet performance standards, mothers are likely to use directiveness, which is subsequently related to an increase in children's academic achievement (Pomerantz \& Eaton, 2001). However, low-achieving elementary school children also seem to be susceptible to disengage from the task when they experience high maternal directiveness, and this disengagement translates into low performance ( $\mathrm{Ng}$, Kenney-Benson, \& Pomerantz, 2004). Yet some other studies show that the effects of maternal directiveness on elementary school children's academic skills do not depend on children's initial skill levels (Grolnick, Gurland, DeCourcey \& Jacob, 2002).

Taken together, the extent to which maternal directiveness predicts gains in children's reading and mathematics might depend on ethnicity and child initial skill levels. Importantly, the moderating role of ethnicity on the relation between directiveness and child outcomes has emerged when comparing European American groups to other ethnic groups (e.g., African American, Chinese, Latino). It is not clear whether significant moderation effects would emerge when comparing four ethnic groups (African American, Dominican, Mexican and Chinese) traditionally considered directive in their parenting style.

\section{The present study}

The main goal of this study was to examine whether maternal writing support, math support, and directiveness in the context of a grocery shopping game predicted gains in children's reading and mathematics achievement from age 5 (T1) to first grade (T2) in a sample of low-income and ethnically diverse families. We addressed three research questions:

1) To what extent do low-income and ethnically diverse mothers provide writing and math support and display directiveness in a grocery shopping game, and are these maternal behaviors related? Based on prior work, we expected low levels of maternal writing and math support and moderate levels of directiveness in the grocery shopping game. We entertained two exploratory hypotheses regarding the association among these behaviors. On the one hand, it was possible that mothers who provided more writing support would also provide more math support and display more directiveness. On the other hand, it was possible that high levels of maternal writing support would not necessarily be associated with high levels of maternal math support or directiveness.

2) Do maternal writing support, math support, and directiveness predict gains in children's reading and mathematics achievement from T1 to T2? In line with prior research, we expected domain-specific associations, such that maternal writing support would uniquely predict gains in children's reading, and maternal math support would uniquely predict gains in children's mathematics. This would indicate that the use of specific strategies and behaviors promote reading and mathematics, not just parents' overall involvement in academic activities at home. Given the scarce literature on maternal directiveness and children's reading and mathematics, we entertained two exploratory hypotheses. On the one hand, it was possible that maternal directiveness would be negatively related to children's achievement. On the other hand, it was possible that maternal directiveness would not bear a significant relation to children's achievement.

3) What role do maternal ethnicity and child skill levels (baseline skills at T1) play in the relation between maternal behaviors and gains in children's reading and mathematics? We explored the moderating role of ethnicity on maternal directiveness but not on maternal writing or math support because prior studies show that these maternal supportive behaviors operate similarly across ethnic communities. We expected that ethnicity would bear no moderating role in the relation between maternal directiveness and children's achievement, given that the four ethnic groups included in the study are traditionally known for embracing a more directive parenting style. Regarding the moderating role of child skills on the relation between these three maternal behaviors and children's reading and mathematics, we entertained two exploratory hypotheses. In line with a compensatory hypothesis (Burchinal, Peisner-Feinberg, Pianta, \& Howes, 2002), children with weaker baseline skills would benefit more from more maternal writing support, math support, and directiveness than children with strong baseline skills. However, in line with a skill-begets-skill hypothesis (Mol, Bus, de Jong, \& Smeets, 2008), children with stronger baseline skills might profit more from more maternal writing support, math support, and directiveness than children with weaker baseline skills.

\section{Method}

\subsection{Participants}

Participants were 212 mothers and their children drawn from a larger longitudinal study of the development of children from low-income, ethnically diverse families living in a large city in the Northeast. Recruitment was conducted at hospitals and public health clinics. Inclusion criteria for mothers were: being at least 18 years of age, not residing in shelters, having lived with the target child since the child's birth, self-identifying as African American, Dominican, Mexicans or Chinese, and children being healthy and full term at their births. Research assistants approached mothers at hospitals and public health clinics, described the study, and asked whether they wanted to participate. For this particular study, we focused on those children who spoke English proficiently at age 5 and in first grade. English proficiency was based on measures of children's language at earlier ages, parents' interviews, assessors' measurements, and children's choice of language during the session. Participants were 57 African Americans, 59 Dominicans, 33 Mexicans and 63 Chinese mothers and their children. All children were 5 years old at the beginning of this study. All of the African American mothers were born in the United States. All of the Chinese mothers, $94 \%$ of the Mexican, and $73 \%$ of the Dominican mothers were born outside the United States. The average monthly family income reported by mothers at the time of the study was $\$ 2024.60$ (after taxes), $S D=\$ 1288.39$, range $=\$ 200-\$ 6500$. On average, mother's age was $27.92(\mathrm{SD}=6.70$, range $=18-45)$.

\subsection{Procedure}

Data were collected at a University lab at two time points: when children were 5 years old (T1) and when children were in first grade (T2). At T1, most children (93\%) were attending school or daycare. Specifically, $8 \%$ had 3-4 years of child center-based experience, $85 \%$ had $1-2$ years of experience, and $6 \%$ had no experience. Average length of time elapsed between T1 and T2 was 15.30 months, $\mathrm{SD}=2.66$, range $=11.5-22.5$ months. At T1, mothers and children were videotaped playing the grocery shopping game (Leyva et al., 2012). In addition, mothers completed a questionnaire about demographic information and home practices. All African American dyads completed the grocery shopping game and questionnaire about demographic information and home practices in English, 39\% of Dominican and 85\% of Mexican dyads completed 
the tasks in Spanish, and 100\% of Chinese dyads completed the tasks in Mandarin or Cantonese. At both time points, children's reading and mathematics were assessed in English using a standardized battery of tests. However, if children chose to answer a question in Spanish or Chinese, they were credited if the response was correct. All participants had the same order of presentation of tasks. Mothers completed the questionnaire while children's academic skills were assessed.

\subsection{Grocery shopping game}

Mothers and children were videotaped playing a game in which they made a grocery list and used the list to go grocery shopping at a pretend store. The task procedure was adapted from Leyva et al. (2012) and was as follows: mothers and children were shown a picture menu with 12 different food items available at the pretend store: broccoli, corn, orange, grapes, cookie, pie, chocolate, lollipop, chicken, egg, potato chips and french fries. Before the game started, children were asked to identify each of the food items; help was offered if needed.

Dyads were provided with four plastic coins for shopping, a blank sheet of paper, and a set of markers and were asked to make a list with food items from the picture menu. The instructions were: "You and your child will play a game. In this game, you will pretend to go grocery shopping. There are four coins, each worth $\$ 1$, so you can only buy four things. You and (child's name) will choose four things you want to buy at the store, ok? You and (child's name) are going to make a list, so you can remember the four things you want to buy." Following previous procedure (Leyva et al., 2012), we said "making a list," rather than "writing a list" to allow dyads to choose the encoding strategy that better fit their child's skills including scribbles, drawings, letters, and a combination of drawings and letters. Once the dyad made the list, they were given a basket to shop for the items at the pretend store. The pretend store consisted of 12 plastic bins, one per food item; each bin contained four plastic food items (e.g., four plastic oranges). Dyads used their list to shop and were asked to insert one coin in a piggy bank for each of the items they placed in the basket. Most dyads (93\%) bought four items; 7\% bought fewer than four items.

\subsection{Measures and coding}

A team of seven trained raters used videos of the grocery shopping game to code for maternal writing support, math support, and directiveness. There were four participant ethnicities (three different languages), and thus it was necessary to include two to three raters per ethnicity for the reliability process. English, Spanish and Chinese (Mandarin and Cantonese) videos were coded by raters who were fluent in the respective language. Raters were first trained by the first author (master coder). During this training, raters went through four rounds of reliability with the master coder; each round entailed a different video. The raters' Kappa index across these four rounds of reliability averaged 0.85 (range $=0.81-0.90$ ). Overall, $15 \%$ of the videos were double-coded by the master coder and a rater; the remaining videos were independently coded by the raters. Only $15 \%$ of the videos were double-coded given the complex scoring system and the need for raters fluent in the targeted languages. On average, each rater coded 25-30 videos. Three reliability checks (one every other week, each one involving 1 video) were conducted with the master coder to ensure that raters continued to be reliable after several weeks of coding. The raters' Kappa index during these reliability checks averaged 0.85 (range $=0.83-0.93$ ).

\subsubsection{Maternal writing support and math support}

Maternal writing support was operationalized as highlighting individual letters and sounds for the child by dictating and sounding out letters or by breaking a word into units of sounds and linking each unit of sound to its corresponding letter. Highlighting individual letters and sounds is important in the context of the grocery shopping game because most children were not independent writers and because some words in the task, such as broccoli, were unfamiliar to them. Coding of maternal writing support was based on the number of food items for which the mother exhibited at least one of the aforementioned behaviors. For example, a mother who dictated and sounded out letters or broke a word into units of sounds and linked each unit of sound to its corresponding letter in one out of four food items received a score of 1 (the maximum score was 4).

Maternal math support was operationalized as counting and simple addition and subtraction calculations, behaviors that were important in the context of the grocery shopping game because dyads could only buy four items. Specifically, counting involved asking the child to count or counting for the child. Simple addition and subtraction calculations involved: a) asking the child to calculate difference in items; for example, "it's four, how many more do we need?" or b) calculating differences in items for the child; for example, "we have three, we got one more to go." Like writing support, math support was coded as presence or absence of these behaviors in each of the four food items. For example, a mother who counted and added items for the child in two out of four food items included on the list received a score of 2 . Importantly, parents were not instructed to use any of these writing- or math-support strategies; they spontaneously engaged in them in the grocery shopping game.

For both maternal writing and math support, if the dyad chose fewer than four food items, the scores were calculated based on a total of four as follows: exhibiting a behavior in one out of three food items would warrant a score of 1.33 , equivalent to $(1 \times 4) / 3$, and exhibiting a behavior in two out of three food items would warrant a score of 2.66 , equivalent to $(2 \mathrm{X} 4) / 3$.

\subsubsection{Maternal directiveness}

Maternal directiveness was operationalized as taking over the child's activity at four critical moments in the task: a) selecting the food items to include on the list, b) encoding (making) the list before going to the pretend store; $\mathrm{c}$ ) decoding (reading) the list at the pretend store; and d) actively using the list, that is, picking up the food items on the list and placing them in the basket. We chose these four moments because they marked the key tasks of the grocery shopping process and were episodes that all dyads engaged in. Coding of maternal directiveness was based on the number of food items for which the mother took over, without help from the child, at each of these four moments. For example, if the mother took over selecting one of the four food items, then the mother was assigned a score of 1 on food selection. A similar procedure was followed to code for the remaining three moments in the task. For example, a mother who took over encoding in three out of the four food items included on the list received a score of 3 on encoding. If the dyad chose fewer than four items, the scores were calculated based on a total of four (e.g., score of 2.66 if two out of three). The final maternal directiveness score was the average of the individual scores obtained in the four critical moments of the task. Maternal behaviors exemplifying high levels of directiveness include the mother telling the child 'we need to buy corn' rather than asking the child 'what should we buy?' and the mother taking the pencil to write out the word for the child rather than allowing the child to write the item on her own. See Appendix A for excerpts of transcripts illustrating high and low levels of maternal directiveness. 


\subsubsection{Children's reading}

Three measures of reading were used: decoding, reading comprehension and vocabulary. Decoding was assessed using the Woodcock-Johnson III (W-J) letter-word identification subtest (Woodcock, McGrew, \& Mather, 2001), which required the child to identify letters of the alphabet and read words. Reading comprehension was assessed using the $\mathrm{W}-\mathrm{J}$ passage comprehension subtest. The initial items of this subtest required the child to match words to pictures (symbolic learning). The remaining items required the child to read a short passage and identify the missing word. Vocabulary was assessed using the Expressive One Word Picture Vocabulary Test (EOW-PVT 4; Brownell, 2012), which required the child to identify the name of pictures representing objects, actions or concepts. Raw scores were used in analyses.

\subsubsection{Children's mathematics}

Two measures of mathematics were used: number calculation and math concepts. Number calculation was assessed using the WJ applied problems subtest (Woodcock et al., 2001). In the applied problems subtest, the child was orally presented with math problems and required to solve them using calculations. Math concepts were assessed using the $\mathrm{W}-\mathrm{J}$ quantitative concepts subtest. The quantitative concepts subtest required the child to identify math terms and number patterns. Raw scores were used in analyses.

\subsubsection{Covariates}

Covariates were: maternal ethnicity (coded as dummy variables for each ethnic group; the reference group was African American), maternal education (in years), child center-based educational experience (number of years in school, including preschool and/or kindergarten), child gender (female; coded as a binary variable), frequency of literacy and math activities at home (5-point scale), time (in months) elapsed between T1 and T2, and children's baseline skills (T1). Mothers reported frequency of literacy and math activities at home (teaching letters, numbers, shapes, and colors, reading books, telling stories, singing songs about letters and numbers, and talking about what is watched on television) using a 5 -point scale as follows: $1=$ never, 2 = rarely, 3 = few times a month, $4=$ few times a week, $5=$ every day. Frequencies were positively and significantly correlated across these activities ( $r$ s ranged from 0.36 to 0.40 , all $p s<0.05$ ); hence, we created a single composite measure of literacy and math activities at home by averaging the responses for each literacy or math activity. Because all children were 5 years old at T1 but were slightly different ages at T2 (first grade), we included time elapsed (in months) between T1 and T2 as a covariate in regression analyses.

Table 1 shows the descriptive statistics for covariates. In preliminary analyses, maternal education, time elapsed between T1 and $\mathrm{T} 2$, and child baseline skills in reading and mathematics (T1) were positively related to child outcomes at $\mathrm{T} 2$. In contrast, child center-based educational experience, child gender and frequency of literacy and math activities at home were not related to child outcomes. Preliminary analysis also showed some differences in maternal behaviors as a function of ethnicity. Table 2 shows the results of these analyses. Dominican mothers provided more writing support than did Chinese mothers; Dominican and African American mothers provided more math support than did Chinese mothers; and African American mothers used more directiveness than did Chinese mothers. No other significant differences were found. Hence, significant covariates were included in subsequent analyses: maternal education, time elapsed between $\mathrm{T} 1$ and $\mathrm{T} 2$, child baseline skills in reading and mathematics, and maternal ethnicity.

\section{Results}

\subsection{Missing data}

There were no missing data on the grocery shopping game $(100 \%$ completion rate). At T1, the average completion rate of child assessments was $98 \%$ ( 1 missing case in decoding, no missing cases in reading comprehension, 11 missing cases in vocabulary, no missing cases in number calculation, and 4 missing cases in math concepts). Missing cases at T1 were due to the child's inattentiveness and errors in task administration. At T2, the average completion rate of child assessments was $86 \%$ (32 missing cases on children's decoding, reading comprehension, vocabulary, number calculations, and math concepts). Missing cases at T2 were the result of errors in task administration and participants who dropped from the study due to change of residence, illness or family issues. The average completion rate of the questionnaire about demographic information and home practices was $96 \%$.

One-way ANOVAs and chi-square tests showed that there were not significant differences in maternal variables (writing support, math support and directiveness), child variables (reading and mathematics) or covariates (maternal education, frequency of literacy and math activities at home, child gender, maternal ethnicity and child center-based educational experience) at T1 between dyads who remained in the project and those who dropped out at T2 (all ps > 0.10). Missing data were handled using listwise deletion given that the dataset was largely complete.

\subsection{Incidence of maternal behaviors}

Our first research question was: To what extent do low-income and ethnically diverse mothers provide writing and math support and display directiveness in a grocery shopping game and are these maternal behaviors related?

There was a wide range of variability in the extent to which mothers provided writing support in the grocery shopping game,

Table 1

Descriptive Statistics (mean; SD in parenthesis) for Covariates.

\begin{tabular}{|c|c|c|c|c|c|}
\hline Covariates & $\begin{array}{l}\text { Total } \\
\mathrm{N}=212\end{array}$ & $\begin{array}{l}\text { African American } \\
n=57\end{array}$ & $\begin{array}{l}\text { Dominican } \\
\mathrm{n}=59\end{array}$ & $\begin{array}{l}\text { Mexican } \\
\mathrm{n}=33\end{array}$ & $\begin{array}{l}\text { Chinese } \\
n=63\end{array}$ \\
\hline $\begin{array}{l}\text { Maternal education } \\
\text { (years) }\end{array}$ & 8.67 (3.07) & $8.04(1.90)$ & $8.76(2.10)$ & $5.21(3.05)$ & $10.98(2.80)$ \\
\hline $\begin{array}{l}\text { Child female } \\
\text { (proportion) }\end{array}$ & $0.46(0.50)$ & $0.42(0.50)$ & $0.42(0.50)$ & $0.52(0.51)$ & $0.49(0.50)$ \\
\hline $\begin{array}{l}\text { Frequency of literacy } \\
\text { and math activities at } \\
\text { home (5-point scale) }\end{array}$ & $3.82(0.70)$ & $4.03(0.70)$ & $3.98(0.68)$ & $3.51(0.67)$ & $3.65(0.62)$ \\
\hline $\begin{array}{l}\text { Child center-based } \\
\text { educational experience } \\
\text { (years) }\end{array}$ & $1.58(0.79)$ & $1.56(0.92)$ & $1.46(0.82)$ & $1.94(0.81)$ & $1.50(0.54)$ \\
\hline $\begin{array}{l}\text { Time elapsed between } \\
\text { T1 and T2 (months) }\end{array}$ & $15.30(2.66)$ & $15.01(2.55)$ & $15.36(2.84)$ & $14.02(1.94)$ & $16.18(2.62)$ \\
\hline
\end{tabular}


Table 2

Results of ANOVAs Describing Differences in Maternal Writing Support, Math Support, and Directiveness in the Grocery Shopping Game at T1 as a Function of Ethnicity.

\begin{tabular}{|c|c|c|c|c|c|}
\hline Maternal variables & $\begin{array}{l}\text { African American } \\
n=57\end{array}$ & $\begin{array}{l}\text { Dominican } \\
\mathrm{n}=59\end{array}$ & $\begin{array}{l}\text { Mexican } \\
\mathrm{n}=33\end{array}$ & $\begin{array}{l}\text { Chinese } \\
n=63\end{array}$ & $F(3,208)$ \\
\hline Writing support & $0.96(1.71)$ & $1.05(1.72)$ & $0.88(1.65)$ & $0.25(0.98)$ & $3.43^{*}$ \\
\hline Math support & $1.40(1.11)$ & $1.17(0.94)$ & $0.90(0.93)$ & $0.46(0.76)$ & $9.95^{* * *}$ \\
\hline Directiveness & $1.05(0.82)$ & $0.76(0.76)$ & $0.84(0.79)$ & $0.53(0.67)$ & $4.82^{* *}$ \\
\hline
\end{tabular}

* $p<0.05$

** $p<0.01$.

*** $p<0.001$

Table 3

Descriptive Statistics (Mean, SD in parenthesis) for Children's Reading and Mathematics W Scores at T1 and T2.

\begin{tabular}{|c|c|c|}
\hline Skills & T1 (Age 5) & T2 (First Grade) \\
\hline $\begin{array}{l}\text { Reading } \\
\text { Decoding } \\
\text { (W-J letter-word identification) } \\
\text { Reading comprehension } \\
\text { (W-J passage comprehension) } \\
\text { Vocabulary } \\
\text { (EOW-PVT) }\end{array}$ & $\begin{array}{l}363.24(29.76) \\
N=211 \\
408.77(17.07) \\
N=212 \\
66.63(16.06) \\
N=201\end{array}$ & $\begin{array}{l}440.99(33.68) \\
\mathrm{N}=180 \\
451.89(19.20) \\
\mathrm{N}=180 \\
58.82(13.26) \\
\mathrm{N}=180\end{array}$ \\
\hline $\begin{array}{l}\text { Mathematics } \\
\text { Number calculation } \\
\text { (W-J applied problems) } \\
\text { Math concepts } \\
\text { (W-J quantitative concepts) }\end{array}$ & $\begin{array}{l}412.39(21.83) \\
\mathrm{N}=212 \\
422.79(13.87) \\
\mathrm{N}=208\end{array}$ & $\begin{array}{l}451.32(16.53) \\
\mathrm{N}=180 \\
467.21(19.87) \\
\mathrm{N}=180\end{array}$ \\
\hline
\end{tabular}

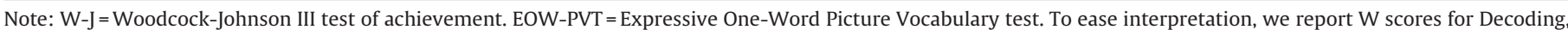
Reading comprehension, Number calculation and Math concepts. Age equivalent scores are provided for Vocabulary. We used raw scores in analyses.

ranging from providing no writing support at all to providing writing support for all four food items. On average, mothers provided writing support for less than one out of the four food items $(M=0.76, \mathrm{SD}=1.55)$. A wide range of support was also observed in maternal math support, from providing no support at all to providing math support for three out of the four food items. On average, mothers provided math support for one out of the four food items $(M=0.98, S D=1.00)$. Similarly, the extent to which mothers displayed directiveness varied, from no directiveness at all to directiveness in three out of the four food items. On average, mothers displayed directiveness for less than one out of the four food items $(M=0.78, \mathrm{SD}=0.77)$. Overall, the percentage of mothers who engaged in target behaviors for at least 1 food item was as follows: $20.28 \%(n=43)$ for maternal writing support, $55.66 \%(n=118)$ for math support, and $75.47 \%$ for directiveness $(n=160)$. We conducted a series of Pearson's correlation tests to determine associations among these maternal behaviors. Maternal writing support and math support were weakly associated, $r=0.16, p<0.05$. Maternal directiveness was weakly related to math support, $r=0.14, p<0.05$, and was not related to writing support, $r=-0.03, p>0.10$.

\subsection{Maternal behaviors in relation to child outcomes}

Our second research question was: Do maternal writing support, math support, and directiveness predict gains in children's reading and mathematics from $\mathrm{T} 1$ to $\mathrm{T} 2$ ?

Descriptive statistics for children's scores in reading and mathematics at $\mathrm{T} 1$ and $\mathrm{T} 2$ are displayed in Table 3 . We provide $\mathrm{W}$ scores for decoding, reading comprehension, number calculation and math concepts. The $\mathrm{W}$ scale is a transformation of the Rasch ability scale, representing both the child's ability level and the task difficulty level (Jaffe, 2009). This is an equal-interval scale that is particularly useful for reporting growth in a skill. The typical range of W scores is between 430 and 550. Overall, children's scores across all four assessments were lower than or close to 430 . This indicates that, overall, children's performance in these assessments at both $\mathrm{T} 1$ and $\mathrm{T} 2$ were below average levels. For vocabulary, we report age-equivalent scores ( $\mathrm{W}$ scores were not available for this test). At T1, children's abilities were at age level; however, at T2, children were below age level.

A series of linear regression analyses were performed to examine the prediction of changes in children's reading and mathematics from $\mathrm{T} 1$ to $\mathrm{T} 2$ by the measures of maternal writing support and math support and directiveness. We regressed children's reading and mathematics outcomes at T2 (separate equations for each reading and mathematics outcome) on maternal writing support, math support and directiveness measured at $\mathrm{T} 1$. We conducted regression analyses in two steps, first entering the covariates and then adding maternal predictors. Tables 4 and 5 show the results of our final regression models including both covariates and maternal predictors. Note that child baseline skills in reading were included in analyses pertaining gains in reading, while child baseline skills in mathematics were included in analyses pertaining gains in mathematics.

\subsubsection{Reading}

We conducted separate analyses on three measures of children's reading achievement: decoding, reading comprehension, and vocabulary. Table 4 summarizes the results of the final regression models. First, we entered covariates into regression models and found that maternal education was positively related to decoding but not to reading comprehension or vocabulary at T2. Child baseline skills (T1) and time elapsed from T1 to T2 were positively associated with all three measures of reading achievement at T2. No other significant effect of covariates was found. Second, we entered maternal predictors into regression models and found that maternal writing support positively predicted gains in children's decoding and reading comprehension, but not vocabulary. Specifically, mothers who highlighted individual letters and sounds in the grocery shopping game at $\mathrm{T} 1$ had children with larger gains in decoding and reading comprehension at T2. The effect size of this predictive relation was small ( $d=0.15$ for decoding; $d=0.18$ for reading comprehension). One unit increase in maternal writing support (i.e., providing writing support for 1 food item) resulted in 
Table 4

Maternal Writing Support, Math Support, and Directiveness at T1 Predicting Gains in Children's Reading Achievement from T1 (Age 5) to T2 (First Grade).

\begin{tabular}{|c|c|c|c|}
\hline & $\begin{array}{l}\text { Decoding } \\
B(\mathrm{SE}) \\
N=179\end{array}$ & $\begin{array}{l}\text { Reading comprehension } \\
B(\mathrm{SE}) \\
N=179\end{array}$ & $\begin{array}{l}\text { Vocabulary } \\
B(\mathrm{SE}) \\
N=173\end{array}$ \\
\hline \multicolumn{4}{|l|}{ Predictors } \\
\hline Maternal writing support at T1 & $0.90^{* *}(0.33)$ & $0.55^{*}(0.22)$ & $0.18(0.47)$ \\
\hline Maternal math support at $\mathrm{T} 1$ & $0.40(0.50)$ & $0.18(0.34)$ & $0.02(0.71)$ \\
\hline Maternal directiveness at $\mathrm{T} 1$ & $-0.59(0.66)$ & $-0.91^{*}(0.43)$ & $0.37(0.94)$ \\
\hline \multicolumn{4}{|l|}{ Covariates } \\
\hline Maternal education & $0.43^{*}(0.20)$ & $0.16(0.13)$ & $0.01(0.28)$ \\
\hline Time elapsed between $\mathrm{T} 1$ and $\mathrm{T} 2$ & $0.60^{* *}(0.20)$ & $0.34^{*}(0.13)$ & $0.84^{* *}(0.28)$ \\
\hline Child baseline skills (T1) & $0.96^{* * *}(0.09)$ & $0.40^{* *}(0.12)$ & $0.74^{* * *}(0.07)$ \\
\hline Dominican & $1.12(1.29)$ & $-0.36(0.87)$ & $0.11(1.83)$ \\
\hline Mexican & $2.56(1.65)$ & $0.02(1.11)$ & $2.37(2.43)$ \\
\hline Chinese & $1.03(1.57)$ & $1.74(1.07)$ & $3.77(2.11)$ \\
\hline
\end{tabular}

Note. $B=$ unstandardized parameter estimate; $\mathrm{SE}=$ standard error. Reference ethnic group is African American.

${ }^{*} p<0.05$.

*** $p<0.01$.

**** $p<0.001$.

Table 5

Maternal Writing Support, Math Support, and Directiveness at T1 Predicting Gains in Children's Mathematics Achievement from T1 (Age 5) to T2 (First Grade).

\begin{tabular}{|c|c|c|}
\hline & $\begin{array}{l}\text { Number calculation } \\
B(\mathrm{SE}) \\
N=179\end{array}$ & $\begin{array}{l}\text { Math concepts } \\
B(\mathrm{SE}) \\
N=175\end{array}$ \\
\hline \multicolumn{3}{|l|}{ Predictors } \\
\hline Maternal writing support at T1 & $0.07(0.15)$ & $0.30(0.20)$ \\
\hline Maternal math support at $\mathrm{T} 1$ & $0.13(0.22)$ & $0.45(0.30)$ \\
\hline Maternal directiveness at T1 & $-0.76^{*}(0.29)$ & $-0.97^{*}(0.39)$ \\
\hline \multicolumn{3}{|l|}{ Covariates } \\
\hline Maternal education & $0.03(0.09)$ & $-0.02(0.12)$ \\
\hline Time elapsed between $\mathrm{T} 1$ and T2 & $0.32^{* * * *}(0.09)$ & $0.39^{*}(0.12)$ \\
\hline Child baseline skills (T1) & $0.42^{* * *}(0.05)$ & $0.41^{* * *}(0.07)$ \\
\hline Dominican & $0.54(0.58)$ & $-0.56(0.77)$ \\
\hline Mexican & $0.01(0.74)$ & $-0.78(0.98)$ \\
\hline Chinese & $1.72^{*}(0.68)$ & $0.92(0.96)$ \\
\hline
\end{tabular}

Note. $B=$ unstandardized parameter estimate; $\mathrm{SE}=$ standard error. Reference ethnic group is African American.

${ }^{* *} p<0.01$.

${ }^{*} p<0.05$.

**** $p<0.001$.

a 0.90 increase in children's decoding and a 0.55 increase in reading comprehension. Maternal directiveness negatively predicted gains in children's reading achievement; mothers who took over the child's activity in the grocery shopping game had children with smaller gains in reading comprehension but not decoding or vocabulary. The effect size of this predictive relation was small $(d=0.15)$. One unit increase in maternal directiveness resulted in a 0.91 decrease in children's reading comprehension.

Importantly, the unique effects of maternal writing support and directiveness maintained, above the significant associations of maternal education, time from $\mathrm{T} 1$ to $\mathrm{T} 2$, child baseline reading skills (T1), and maternal ethnicity. The effect size of this predictive relation was small $(d=0.15)$. One unit increase in maternal directiveness resulted in a 0.59 decrease in children's decoding and a 0.91 decrease in children's reading comprehension. No crossdomain effects of maternal math support were detected; mothers who used more counting and calculating strategies in the grocery shopping game did not have children with larger gains in decoding, reading comprehension or vocabulary at $\mathrm{T} 2$.

\subsubsection{Mathematics}

We conducted separate analyses on two measures of children's mathematics achievement: number calculation and math concepts. Table 5 summarizes the results of the final regression models. First, we entered covariates into regression models and found that maternal education was not associated with children's number cal- culation or math concepts at T2. Child baseline skills (T1) and time elapsed from T1 to T2 were positively related to both number calculation and math concepts at T2. Maternal ethnicity was associated with number calculation but not math concepts at T2; Chinese children scored better in number calculation than did African American children. No other significant effect of covariates was found.

Second, we added maternal predictors and found that maternal math support did not significantly predict gains in children's number calculation or math concepts. Mothers who used more counting and calculating strategies in the grocery shopping game did not have children with larger gains in mathematics. However, maternal directiveness negatively predicted gains in number calculation and math concepts. Mothers who took over the child's activity in the grocery shopping game had children with smaller gains in both number calculation and math concepts. The effect size of this predictive relation was small $(d=0.16$ for both number calculation and math concepts). One unit increase in maternal directiveness resulted in a 0.76 decrease in children's number calculation and a 0.97 decrease in children's math concepts. This negative effect of maternal directiveness was present after accounting for the positive effects of time elapsed from T1 to T2 and child baseline mathematics skills (T1). Similarly to our analyses on growth in reading, no cross-domain effects of maternal writing support were found; mothers who highlighted individual letters and sounds did not have children with larger gains in mathematics at T2. 
In subsequent analyses, we tested for interaction effects among maternal predictors and found no significant interactions, all $p s>0.10$. Hence, the positive effect of maternal writing support on children's decoding and reading comprehension did not depend on levels of directiveness, and the negative effect of maternal directiveness on children's number calculation and math concepts did not depend on levels of math support.

\subsection{The role of maternal ethnicity and child skill levels}

Our third research question was: What role do maternal ethnicity and child skill levels (baseline skills at T1) play in these maternal behaviors and their relation to gains in children's reading and mathematics? We tested for interaction effects of maternal ethnicity (entered as a series of dummy variables; the reference group was African American) and maternal directiveness on children's reading or mathematics and found no significant interaction effects, all $p s>0.10$. Similarly, we did not find significant interaction effects of child baseline skills and maternal behaviors (writing support, math support, and directiveness) on children's reading or mathematics, all $p s>0.10$. Taken together, these findings indicate that maternal ethnicity and child skills levels did not play a moderating role in the relation between maternal behaviors and child outcomes

\section{Discussion}

We investigated how mothers fostered the development of children's reading and mathematics in the context of a grocery shopping game in a sample of African American, Dominican, Mexican and Chinese families. Across all four ethnic groups and child skill levels, maternal writing support predicted gains in children's decoding and reading comprehension from age 5 (T1) to first grade (T2). However, maternal math support in the grocery shopping game did not predict gains in children's number calculation or math concepts from T1 to T2. Across all four ethnicities and child skill levels, the more mothers took over the child's activity in the grocery shopping game, the smaller were the gains in children's reading comprehension, number calculation, and math concepts from T1 to $\mathrm{T} 2$.

\subsection{Incidence of maternal behaviors}

As expected, we observed low incidence of maternal writing and math support and directiveness. On average, mothers provided writing support and math support and displayed directiveness for less than 1 out of the four food items on the list. Mothers who provided more writing support were not necessarily providing more math support or displaying more directiveness. The low incidence of maternal writing and math support and directiveness can be explained in several ways.

First, mothers might have had competing goals when playing the grocery shopping game with their children, and explicit teaching of reading and mathematics was only one of these goals. In fact, several mothers engaged in teaching of other life-relevant concepts during the grocery shopping game, such as making healthy versus unhealthy food choices. We intentionally designed the grocery shopping game to be a semi-structured task, and did not present it as a school homework activity, because we were interested in examining how low-income and ethnically diverse mothers and their children approached a game that resembled an everyday activity involving reading and mathematics. Our results are in line with previous research indicating that low-income parents tend to display more support for academic skills when the task is more structured and similar to what school homework would look like than when the task is less structured and does not resemble school homework (Vandermaas-Peeler \& Pittard, 2014).
Second, mothers might have refrained from providing high levels of writing support because they perceived that their 5-year-old children were not ready for it. Studies have shown that parents' perceptions about what is age appropriate and their sensitivity to children's competence influence the extent to which they provide support during a joint task (Aram, 2007; Bindman et al., 2014). In light of this research and in an attempt to be culturally sensitive to our diverse sample, we specifically asked mothers to 'make a list' rather than 'write a list.' A significant percentage of dyads (34\%) used a combination of drawings, letters and numbers to make their list. This might explain why mothers were not using writingsupportive strategies for all of the food items on the list.

Third, mothers might not have been aware of specific ways they can foster writing and math in the context of grocery shopping. Others have shown that even middle-class parents may be unaware of how children develop reading and math skills; for example, the important connection between phonological awareness (parsing out units of sounds in words) and reading is not always obvious to middle-income European American parents (Bindman et al., 2014; Skibbe et al., 2013) and sometimes, not even to preschool teachers (Cunningham, Perry, Stanovich, \& Stanovich, 2004).

Finally, it is possible that parents did not engage in more math support because the grocery shopping game involved small numbers. Specifically, dyads were given 4 coins (each worth \$1) and the price of every item was $\$ 1$. Parents have been shown to be more likely to provide math support when their 4- to 5-year-olds count large numbers than when they count small numbers (Benigno \& Ellis, 2004). In future work, it would be important to include larger numbers in the grocery shopping game; for example, give dyads more coins or have different prices for different food items at the pretend store.

\subsection{Maternal behaviors in relation to child outcomes}

\subsubsection{Writing support}

Despite relatively low prevalence of writing support behaviors in this sample, mothers' provision of writing support was related to children's gains in decoding and reading comprehension. This association maintained after controlling for significant covariates including maternal education, time elapsed between T1 and T2 (i.e., child age), and child baseline skills. Our results contribute to the literature (Aram \& Levin, 2001, 2004; Bindman et al., 2014; Lin et al., 2009; Skibbe et al., 2013) by establishing the importance of this particular writing support strategy, namely highlighting individual letters and sounds, for the development of children's reading skills across four ethnic groups not previously studied in the literature (low-income African American, Dominican, Mexican and Chinese). Maternal writing support was not related to growth in vocabulary, which is consistent with prior research indicating that mothers are not simultaneously teaching letter-word correspondence and vocabulary (Bindman et al., 2014; Lin et al., 2012; Sénéchal et al., 1998; Skibbe et al., 2013).

\subsubsection{Math support}

Contrary to expectations, maternal math support in the grocery shopping game did not predict gains in children's mathematics achievement. The discrepancy in the grocery task demands related to math versus writing and reading might explain why we detected significant associations between maternal writing support and children's reading achievement but we did not detect associations between maternal math support and growth in children's mathematics. While the range of difficulty of math calculations (counting, adding, subtracting) with four coins was limited, the range of difficulty of writing and reading was wider (food items ranged from 3-letter words to more than 8 letters). 
A recent study using nationally representative data showed that kindergarten teachers spend most of their time teaching math content that kindergarten children already know before school entry, namely, basic counting and recognition of geometric shapes. Exposure to mathematical content that was at or below the knowledge and skills that kindergarten children already had at school entry was associated with lower mathematics achievement at the end of kindergarten (Engel, Claessens, \& Finch, 2013). For children who had already mastered basic skills (counting and recognition of geometric shapes) more time spent on this content in the classroom was detrimental to their math achievement, presumably because it meant less time learning more sophisticated math content that would translate into more gains in their mathematics achievement during the kindergarten year. It is possible that, in our study, maternal math support focused on content that children had already acquired; therefore, was not predictive of gains in children's mathematics achievement in first grade. Controlling for range of difficulty across these two domains (math and reading and writing) in the grocery shopping game would be a fruitful direction for future research.

Previous studies examining how parents support children's math at home have yielded mixed results. On the one hand, parents' reports of frequency of math activities at home, including everyday activities such as cooking and shopping, are consistently related to children's mathematics achievement across different ethnicities and SES (LeFevre et al., 2009; Ramani et al., 2015). On the other hand, the types of math-support strategies that parents engage in with their 3- to 5-year-olds have not shown consistent associations with children's mathematics achievement (Bjorklund et al., 2004; Skwarchuk, 2009). A focus on math talk rather than math-support strategies may be one promising avenue to better understand the complex relation between parental math support at home and the development of math abilities. Adult math talk (amount of mathematical input in the speech) is associated with children's mathematics achievement in families from diverse ethnic and SES background (Klibanoff et al., 2006; Levine, Suriyakham, Rowe, Huttenlocher, \& Gunderson, 2010; Ramani et al., 2015). Hence, it is possible that it is the sheer amount of math talk, rather than the specific strategies used by parents, that is most relevant to how children learn and practice mathematics at home.

\subsubsection{Directiveness}

Across all four ethnic groups and child skill levels, maternal directiveness (taking over the child's activity in the grocery shopping game) was negatively associated with gains in children's reading comprehension, number calculation, and math concepts. This result was present even when accounting for significant covariates including maternal education, time elapsed between T1 and T2 (child age), and child baseline skills. Mothers displayed directive behaviors relatively rarely (for less than one out of the four food items on the list), yet their level of directiveness was negatively related to gains in children's reading comprehension, number calculation and math concepts. It is possible that children were accustomed to exercising control during academic tasks in school and had begun to internalize the U.S. societal values of independence and autonomy. As a result, children might have interpreted mothers' attempts to control the grocery shopping game as attempts to hinder their autonomy and competence (Ispa et al., 2004), which might have limited their opportunities to learn. Mothers who take over the child's task may hinder children's ability to make connections between concepts and elements in the task (Hubbs-Tait et al., 2002). Maternal directivenes might also affect children's task involvement. Children who are given more freedom of choice in writing and reading tasks report more curiosity, involvement, and perceived competence than children who are not given such freedom (Gutman \& Sulzby, 2000; Ng, Guthrie, Van
Meter, McCann, \& Alao, 1998). Furthermore, the more engaged children are in number-related tasks, the better they score in a standardized math test (Vandermaas-Peeler \& Pittard, 2014). Contrary to prior research, we did not find that maternal directiveness was negatively related to children's decoding (Aram \& Levin, 2001; Skibbe et al., 2013) or vocabulary (Hubbs-Tait et al., 2002; Olson et al., 1992). In future research, we hope to assess levels of child attention and engagement in the grocery shopping game as a way to further understand the relations among maternal directiveness and child academic achievement.

\subsection{The role of maternal ethnicity and child skill levels}

We found no evidence supporting the moderating role of ethnicity on the relation between maternal directiveness and children's reading and mathematics. Our variable 'ethnicity' was a proxy for a more complex set of factors not examined in this study, including culture, identity, beliefs and values, immigration and transnational experience. It is possible that a more in-depth study of this complex set of factors would yield a different outcome. Additionally, most of the studies reporting a significant moderating effect of maternal ethnicity on the relation between maternal directiveness and child outcomes have used European American families as their reference group (for a review see Ispa et al., 2004). In this study, we compared four ethnic groups that have been traditionally known for embracing a more directive parenting style (Carlson \& Harwood, 2003; Ispa et al., 2004). Hence, it is possible that moderating effects of ethnicity are only evident when compared to a group that is generally less directive, such as European Americans (Whiteside-Mansell, Bradley, Owen, Randolph, \& Cauce, 2003).

Finally, we did not find that child's level of skills (baseline reading and math skills at T1) moderated the associations between maternal writing support and children's reading or between maternal math support and children's mathematics achievement. This finding warrants further investigation. A more in-depth analysis of how children elicited and responded to mothers' writing and math support in the grocery shopping game would help clarify the role of child skill level. Controlling for level of difficulty in math and reading and writing might also shed some light on the presence (or not) of these moderating effects. Information about parents' perceptions of children's competence and parents' knowledge of how children develop reading and mathematics may also help reveal whether and how child skill levels play a role in this relation. Child skill levels also did not moderate the relation between maternal directiveness and children's reading and mathematics. This lack of moderation, however, does not preclude the possibility that with a different kind of task moderation might be found, as has been the case with some prior studies (Gauvain \& Perez, 2008).

\subsection{Contributions to existing literature}

One of the main contributions of this study is the examination of maternal writing support, math support, and directiveness in the context of a grocery shopping game. By framing the task as a grocery shopping game, the activity becomes meaningful and connected to the family's everyday lives and knowledge. As a result, children and parents are genuinely engaged in the task and interested in completing it. When playing the grocery shopping game, families not only focus on supporting writing and math skills but may also discuss healthy food eating habits (e.g., "I think you got enough snacks, how about getting a fruit?"), personal experiences (e.g., "these are like the oranges you ate yesterday in school"), and moral and social rules (e.g., "first we got to pay and then we can take it home"). Importantly, we acknowledge that there are differences between performing a real-world task (going grocery shopping) and playing 
the grocery shopping game in a researcher's laboratory and that our task does not necessarily mirror real-life shopping.

Framing the task as a grocery shopping game is also an excellent opportunity for children to simultaneously make use of several symbolic systems, including writing, reading, and mathematics, and to think about them as complementary tools to solve a common problem or reach a common goal. Although in school settings, writing, reading, and mathematics are typically presented as separate subjects, in real-life settings we frequently use them jointly to solve everyday problems.

Finally, by framing the task as a grocery shopping game we bring together two key aspects of symbolic understanding: a) mastering the conventions of print, such as knowing the letter names, letter sounds, and numbers; and b) understanding the communicative function of print, that is, appreciating that one writes in order to read, and that one reads what has been written (DeLoache, 2000; Namy \& Waxman, 2005). It is not obvious to young children that both reading and writing are part of a single process (Tolchinsky, 2003); hence, activities requiring children to switch between adopting the role of the producer of the symbol (writer) and the user of the symbol (reader), such as the grocery shopping game, might be key to reading and mathematics development.

\subsection{Educational implications}

The low incidence of maternal writing and math support and directiveness has important implications for professionals working with low-income and ethnically diverse populations. Even when provided with rich opportunities, parents are not always ready or mindful about ways they can support their children's academic skills in situations that resemble everyday activities, such as the grocery shopping game. Parents might need encouragement from educators or practitioners to provide their children with specific support. Parents might also need more training (knowledge) about effective strategies they could use with their children to foster their academic skills.

In this study, we have identified a set of parental behaviors and strategies that are positively related to children's reading and mathematics in the context of a grocery shopping game. This identification is central to program design and ultimately, to program effectiveness, as the most sustainable and effective parent-focused programs are those that add to pre-existing parental behaviors and strategies rather than imposing new and unrelated series of behaviors to family dynamics (Fullilove, Green, \& Fullilove, 2000). Based on the identification of this set of behaviors and strategies using the grocery shopping game, we have designed an intervention program that uses everyday, family food practices (such as grocery shopping and cooking) as learning opportunities to enhance children's academic skills.

We are currently conducting a feasibility study of this intervention program for low-income families. This study is a first step towards understanding the directionality of the associations between maternal behaviors in the grocery shopping game and children's reading and mathematics achievement. Communitybased programs have documented the importance of capitalizing on family food routines to enhance the knowledge, skills and wellbeing of both parents and children (Fullilove et al., 2000; Thomas \& Irwin, 2011). Family food routines, including grocery shopping, are promising and overlooked venues through which family prevention programs can improve children's abilities to learn and succeed in school.

\subsection{Limitations}

Our sample of low-income African American, Dominican, Mexican, and Chinese families is not representative of these populations nationally. Hence, caution should be exercised when generalizing the results of our study to ethnic and immigrant-origin groups in the United States. Although children's center-based educational experience before T1 (preschool) was included as a potential covariate, we did not measure or account for school quality between T1 and T2. School quality plays a substantial role in the growth of children's reading and mathematics (Burchinal et al., 2002; Leyva et al. (2015); Mashburn et al., 2008; Weiland, Ulvestad, Sachs, \& Yoshikawa, 2013). In future studies, it would be important to control for this factor. We did not include a standardized measure of children's independent writing skills. In future studies, it might be important to include it to further understand how maternal writing support relates to gains in children's reading skills. We focused on a specific aspect of maternal directiveness, that is, whether the mother took over the child's activity in four critical moments of the grocery shopping game. Other behaviors that reflect maternal control, such as management of the child's attention and behavior should be included in future studies. We assessed maternal writing support, math support, and directiveness in the context of a grocery shopping game. In the future, it would be important to assess how parents create learning opportunities for children to develop their reading and mathematics skills during actual grocery shopping and other everyday, family food routines such as cooking. We did not have a measure of fidelity about whether research assistants followed the script explaining the grocery shopping game to mothers. In future research, it would be important to do so.

Despite these limitations, this study shows that the constructs of maternal writing support, math support and directiveness are predictors of gains in children's reading and mathematics achievement. Furthermore, the predictive validity of these maternal constructs was evident across four different ethnicities from low-income backgrounds.

\section{Acknowledgments}

This project was conducted at New York University's Center for Research on Culture, Development, and Education (CRCDE) and funded by the National Science Foundation - Behavioral and Cognitive Sciences Grant 021859 and the National Science Foundation - Integrative Research Activities for Developmental Science Grant 0721383 . We are grateful to the mothers and children who participated in our research over the years. We appreciate the contributions of the following students: Casilda Suarez, Claudia Juliao, Emerald Shee, Yana Kuchirko, Meret Hofer, Jee Young Noh, Elizabeth Epstein, Magdalena Podgorny, Shella Marder, Miyoung Lee, Maria Melendez, Florie Ng, Eva Liang, Irene Wu, and Melissa Quispe. Yoshikawa's work on this paper was partially supported by a grant from the NYU Abu Dhabi Research Institute to the Global TIES for Children Center at New York University.

\section{Appendix A. Excerpts of transcripts illustrating low and high scores on maternal directiveness in the grocery shopping game}

Low directiveness example

*MOT What else you want to buy at the store?

*MOT One more thing

*MOT What should we buy?

${ }^{*} \mathrm{CHI}$ Corn! corn!

${ }^{*}$ MOT You wanna buy corn?

${ }^{*} \mathrm{CHI} \quad$ Yeah

*MOT Corn. ..so what does corn start with?

*MOT Corn sounds like cookie 
${ }^{*} \mathrm{CHI} \quad \mathrm{Hey}$ ! we have four [the child explains that they already have 4 items]

*MOT Let's count them

${ }^{*} \mathrm{CHI}$ One

${ }^{*} \mathrm{CHI}$ Two

${ }^{*} \mathrm{CHI}$ Three

*MOT Hmm...there's one more, you're short! [the mother explains that they need one more item on the list to complete 4]

*MOT Corn

*MOT /c/[mom sounds out letter C]

${ }^{*} \mathrm{CHI} \quad \mathrm{K}$ ?

*MOT Or?

*MOT /c/ [mom sounds out letter $C$ again $]$

${ }^{*} \mathrm{CHI} \quad \mathrm{C}$ ?

*MOT [nods yes]

${ }^{*} \mathrm{CHI} \quad$ [writes letter C]

*MOT [mom sounds out letters, O, R, N as child writes them]

${ }^{*}$ MOT You spelled corn by yourself!

*MOT Now you wanna draw the corn?

${ }^{*} \mathrm{CHI} \quad$ Uh huh

\begin{tabular}{|c|c|}
\hline *MOT & Ok, we need broccoli \\
\hline${ }^{*} \mathrm{CHI}$ & [child grabs a marker] \\
\hline *MOT & $\begin{array}{l}\text { [mother sounds out and then dictates the following letters } \\
\mathrm{B}, \mathrm{R}, \mathrm{O} \text { ] }\end{array}$ \\
\hline${ }^{*} \mathrm{CHI}$ & [child writes the letters $B, R, O$ ] \\
\hline *MOT & [mother sounds out and then dictates the letter C] \\
\hline${ }^{*} \mathrm{CHI}$ & How you do it? \\
\hline *MOT & Like/c/...cat \\
\hline${ }^{*} \mathrm{CHI}$ & [child writes the letter $\mathrm{C}$ ] \\
\hline *MOT & [mother sounds out and dictates $\mathrm{O}, \mathrm{L}, \mathrm{I}]$ \\
\hline${ }^{*} \mathrm{CHI}$ & [child writes the letters $\mathrm{O}, \mathrm{L}, \mathrm{I}$ ] \\
\hline *MOT & $\begin{array}{l}\text { One, two, three [mother counts number of items on the } \\
\text { list] }\end{array}$ \\
\hline *MOT & $\begin{array}{l}\text { Okay you got one more [mother explains to child that they } \\
\text { need one more item on the list to complete } 4 \text { ] }\end{array}$ \\
\hline *MOT & We need eggs \\
\hline${ }^{*} \mathrm{CHI}$ & $\begin{array}{l}\text { I want all of these [child points to all items on picture } \\
\text { menu] }\end{array}$ \\
\hline *MOT & No, you can't pick all of those, it has to be four \\
\hline${ }^{*} \mathrm{CHI}$ & Okay, eggs \\
\hline *MOT & [mother dictates the letter E] \\
\hline${ }^{*} \mathrm{CHI}$ & [child writes the letter E] \\
\hline *MOT & [mother sounds out and dictates the letter $\mathrm{G}$ ] \\
\hline${ }^{*} \mathrm{CHI}$ & How you do a $G$ ? \\
\hline *MOT & $\mathrm{G}$ is a little circle \\
\hline${ }^{*} \mathrm{CHI}$ & [child makes a letter that resembles Q] \\
\hline *MOT & No! that's Q! \\
\hline *MOT & $\begin{array}{l}\text { like that [mother takes marker from child and writes the } \\
\text { word EGG] }\end{array}$ \\
\hline${ }^{*} \mathrm{CHI}$ & Okay \\
\hline
\end{tabular}

Note. ${ }^{*}$ MOT $=$ mother $;{ }^{*} \mathrm{CHI}=$ child. Both mothers received high scores in writing and math support but the first mother received a low score on directiveness while the second mother received a moderate score. These two excerpts only illustrate the first two critical moments of the task (selecting food and encoding the list); the other two moments (decoding and picking up food) were not included here.

\section{References}

Anderson, A. (1997). Families and mathematics: A study of parent-child interactions. Journal for Research in Mathematics Education, 17, 484-511. http:// dx.doi.org/10.2307/749684

Aram, D. (2007). Sensitivity and consistency of maternal writing mediation to twin kindergartners. Early Education and Development, 18, 71-92. http://dx.doi.org/ $10.1080 / 10409280701274733$

Aram, D., \& Levin, I. (2001). Mother-child joint writing in low SES. Sociocultural factors, maternal mediation, and emergent literacy. Cognitive Development, 16 831-852. http://dx.doi.org/10.1016/S0885-2014(01)00067-3

Aram, D., \& Levin, I. (2004). The role of maternal mediation of writing to kindergartners in promoting literacy in school: A longitudinal perspective. Reading and Writing, 17, 387-409. http://dx.doi.org/10.1023/B:READ. 0000032665.14437.e0

Baroody, A. J., Lai, M. L., \& Mix, K. S., (2006). The development of young children's early number and operation sense and its implications for early childhood education. Handbook of Research on the Education of Young Children, 2, 187-221. Retrieved from https://www.researchgate.net/profile/Arthur_ Baroody/publication/232576354_The_Development_of_Young_Children's_Early_ Number_and_Operation_Sense_and_its_Implications_for_Early_Childhood_ Education/links/55f08e2c08ae199d47c2173d.pdf.

Baroody, A. J., Feil, Y., \& Johnson, a. R. (2007). An alternative reconceptualization of procedural and conceptual knowledge. Journal of Research in Mathematics Education, 38, 115-131. http://dx.doi.org/10.1007/s10648-015-9302x

Benigno, J., \& Ellis, S. (2004). Two is greater than three: Effects of older siblings on parental support of preschoolers' counting in middle-income families. Early Childhood Research Quarterly, 19, 4-20. http://dx.doi.org/10.1016/j.ecresq. 2004.01.006

Bindman, S. W., Skibbe, L. E., Hindman, A. H., Aram, D., \& Morrison, F. J. (2014). Parental writing support and preschoolers' early literacy, language, and fine motor skills. Early Childhood Research Quarterly, 29, 614-624. http://dx.doi.org/ 10.1016/j.ecresq.2014.07.002

Bjorklund, D. F., Hubertz, M. J., \& Reubens, A. C. (2004). Young children's arithmetic strategies in social context: How parents contribute to children's strategy development while playing games. International Journal of Behavioral Development, 28, 347-357. http://dx.doi.org/10.1080/01650250444000027

Blevins-Knabe, B., \& Musun-Miller, L. (1996). Number use at home by children and their parents and its relationship to early mathematical performance. Early Development \& Parenting, 5, 35-45. http://dx.doi.org/10.1002/(SICI)10990917(199603)5:1<35:AID-EDP113>3.0.CO;2-0

Brody, G. H., \& Flor, D. L. (1988). Maternal resources, parenting practices, and child competence in rural, single-parent African American families. Child Development, 69, 803-816. http://dx.doi.org/10.1111/j.1467-8624.1998. tb06244.x

Brownell, R. (2012). EOWPVT-4: Expressive one-word picture vocabulary test (4th ed.). Novato, CA: Academic Therapy Publications.

Burchinal, M., Peisner-Feinberg, E., Pianta, R., \& Howes, C. (2002). Development of academic skills from preschool through second grade: Family and classroom predictor of developmental trajectories. Journal of School Psychology, 40, 415-436. http://dx.doi.org/10.1016/S0022-4405(02)00107-3

Burns, M., \& Casbergue, R. (1992). Parent-child interaction in a writing context. Journal of Reading Behavior, 20, 289-312. http://dx.doi.org/10.1080/ 10862969209547779

Carlson, V. J., \& Harwood, R. L. (2003). Attachment, culture, and the caregiving system: The cultural patterning of everyday experiences among Anglo and Puerto Rican mother-infant pairs. Infant Mental Health Journal, 24, 53-73. http://dx.doi.org/10.1002/imhj.10043

Chao, R. K. (2001). Extending research on the consequences of parenting style for Chinese Americans and European Americans. Child Development, 72, 1832-1843. http://dx.doi.org/10.1111/1467-8624.00381

Connor, C. M., Morrison, F. J., \& Katch, L. E. (2004). Beyond the reading wars: Exploring the effect of child-instruction interactions on growth in early reading. Scientific Studies of Reading, 8, 305-336. http://dx.doi.org/10.1207/ s1532799xssr0804_1

Cooper, H., Lindsay, J., \& Nye, B. (2000). Homework in the home: How student, family, and parenting-style differences relate to the homework process. Contemporary Educational Psychology, 25, 464-487. http://dx.doi.org/10.1037/ edu0000032

Culp, A. M., Hubbs-Tait, L., Culp, R. E., \& Starost, H. (2001). Maternal parenting characteristics and school involvement: Predictors of kindergarten cognitive competence among Head Start children. Journal of Research in Childhood Education, 15, 5-17. http://dx.doi.org/10.1080/02568540009594772

Cunningham, A. E., Perry, K. E., Stanovich, K. E., \& Stanovich, P. J. (2004). Disciplinary knowledge of K-4 teachers and their knowledge calibration in the domain of early literacy. Annals of Dyslexia, 54, 139-167. http://dx.doi.org/10. 1007/s11881-004-0007-y

DeBaryshe, B. D., Buell, M. J., \& Binder, J. C. (1996). What a parent brings to the table: Young children writing with and without parental assistance. Journal of Literacy Research, 28, 71-90. http://dx.doi.org/10.1080/10862969609547911

DeLoache, J. S. (2000). Dual representation and young children's use of scale models. Child Development, 71, 329-338. http://dx.doi.org/10.1111/1467-8624. 00148

Dickinson, D. K., McCabe, A., Anastasopoulos, L., Peisner-Feinberg, E. S., \& Poe, M. D. (2003). The comprehensive language approach to early literacy: The interrelationships among vocabulary, phonological sensitivity, and print 
knowledge among preschool-aged children. Journal of Educational Psychology, 95, 465-481. http://dx.doi.org/10.1037/0022-0663.95.3.465

Duncan, G., Dowsett, C., Claessens, A., Magnuson, K., Huston, A., Klebanov, P., et al. (2007). School readiness and later achievement. Developmental Psychology, 43 1428-1446. http://dx.doi.org/10.1037/0012-1649.43.6.1428

Duncan, G., \& Murnane, R. (2014). Restoring opportunity: The crisis of inequality and the challenge for American Education. Cambridge, MA: Harvard Education Press.

Durkin, K., Shire, B., Riem, R., Crowther, R. D., \& Rutter, D. R. (1986). The social and linguistic context of early number word use. British Journal of Developmental Psychology, 4, 269-288. http://dx.doi.org/10.1111/j.2044-835X.1986.tb01018.x

Engel, M., Claessens, A., \& Finch, M. A. (2013). Teaching students what they already know? The (mis)alignment between mathematics instructional content and student knowledge in kindergarten. Educational Evaluation and Policy Analysis, 35, 157-178. http://dx.doi.org/10.3102/0162373712461850

Fullilove, R., Green, L., \& Fullilove, M. (2000). The family to family program: A structural intervention with implications for the prevention of HIV/AIDS and other community epidemics. AIDS, 14, S63-S67. http://dx.doi.org/10.1016/j. jadohealth.2013.11.004

Gauvain, M., \& Perez, S. M. (2008). Mother-child planning and child compliance. Child Development, 79, 761-775. http://dx.doi.org/10.1111/j.1467-8624.2008. 001156.x

Gibson-Davis, C. M., \& Gassman-Pines, A. (2010). Early childhood family structure and mother-child interactions: Variation by race and ethnicity. Developmental Psychology, 46, 151-164. http://dx.doi.org/10.1037/a0017410

Grolnick, W. S., Gurland, S. T., DeCourcey, W., \& Jacob, K. (2002). Antecedents and consequences of mothers' autonomy support: An experimental investigation. Developmental Psychology, 38, 143-155. http://dx.doi.org/10.1037//0012-1649. 38.1.143

Gutman, L., \& Sulzby, E. (2000). The role of autonomy-support versus control in writing behaviors of African American kindergarten children. Reading Research and Instruction, 39, 170-184. http://dx.doi.org/10.1080/19388070009558319

Hubbs-Tait, L., Culp, A. M., Culp, R. E., \& Miller, C. E. (2002). Relation of maternal cognitive stimulation, emotional support, and intrusive behavior during Head Start to children's kindergarten cognitive abilities. Child Development, 73, 110-131. http://dx.doi.org/10.1111/1467-8624.00395

Huntsinger, C. S., Jose, P. E., Larson, S. L., Balsink Krieg, D., \& Shaligram, C. (2000), Mathematics, vocabulary, and reading development in Chinese American and European American children over the primary school years. Journal of Educational Psychology, 92, 745-760. http://dx.doi.org/10.1037/0022-0663.92. 4.745

Ispa, J. M., Fine, M. A., Halgunseth, L. C., Harper, S., Robinson, J., Boyce, L., et al. (2004). Maternal intrusiveness, maternal warmth, and mother-toddler relationship outcomes: Variations across low-income ethnic and acculturation groups. Child Development, 75, 1613-1631. http://dx.doi.org/10.1111/j.14678624.2004.00806.x

Jaffe, L. E. (2009). Development, interpretation, and application of the W score and the relative proficiency index (Woodcock-Johnson III Assessment Service Bulletin No. 11). Rolling Meadows, IL: Riverside Publishing.

Keels, M. (2009). Ethnic group differences in Early Head Start parents' parenting beliefs and practices and links to children's early cognitive development. Early Childhood Research Quarterly, 24, 381-397. http://dx.doi.org/10.1016/j.ecresq. 2009.08.002

Klibanoff, R. S., Levine, S. C., Huttenlocher, J., Vasilyeva, M., \& Hedges, L. V. (2006). Preschool children's mathematical knowledge: The effect of teacher math talk Developmental Psychology, 42, 59-69. http://dx.doi.org/10.1002/ddrr.46

LeFevre, J. A., Fast, L., Skwarchuk, S. L., Smith-Chant, B. L., Bisanz, J., Kamawar, D. et al. (2010). Pathways to mathematics: Longitudinal predictors of performance. Child Development, 81, 1753-1767. http://dx.doi.org/10.1111/j. 1467-8624.2010.01508.x

LeFevre, J., Skwarchuk, S., Fast, L., Smith-Chant, B., Kamawar, D., \& Bisanz, J. (2009). Home numeracy experiences and children's math performance in the early school years. Canadian Journal of Behavioral Science, 41, 55-66. http://dx.doi. org/10.1037/a0014532

Levine, S. C., Suriyakham, L. W., Rowe, M. L., Huttenlocher, J., \& Gunderson, E. A. (2010). What counts in the development of young children's number knowledge? Developmental Psychology, 46, 1309-1319. http://dx.doi.org/10. 1037/a0019671

Leyva, D., Reese, E., \& Wiser, M. (2012). Early understanding of the functions of print: Parent-child interaction and preschoolers' notating skills. First Language, 32, 301-321. http://dx.doi.org/10.1177/0142723711410793

Leyva, D., Weiland, C., Barata, C., Yoshikawa, H., Snow, C., Trevino, E., \& Rolla, A. (2015). Teacher-child interactions in Chile and their associations with prekindergarten outcomes. Child Development, 86, 781-799. http://dx.doi.org/ 10.1111/cdev.12342

Lin, D., McBride, C., Aram, D., Levin, I., Cheung, R. Y. M., Chow, Y. Y. Y., et al. (2009). Maternal mediation of writing in Chinese children. Language and Cognitive Processes, 24, 1286-1311. http://dx.doi.org/10.1080/01690960801970615

Lin, D., McBride-Chang, C., Aram, D., Shu, H., Levin, I., \& Cho, J. R. (2012). Maternal mediation of word writing in Chinese across Hong Kong and Beijing. Journal of Educational Psychology, 104, 121-137. http://dx.doi.org/10.1037/a0025383

Lindahl, K. M., \& Malik, N. M. (1999). Marital conflict, family processes, and boys' externalizing behavior in Hispanic American and European American families. Journal of Clinical Child Psychology, 28, 12-24. http://dx.doi.org/10.1207/ s15374424jсcp28012

Maccoby, E., \& Martin, E. J. A. (1983). Socialization in the context of the family: Parent-child interaction. In E. M. Hetherington (Ed.), Handbook of child psychology, Vol. 4: Socialization, personality, and social development (4th ed., pp. 1-101). New York: Wiley.

Manolitsis, G., Georgiou, G., \& Tziraki, N. (2013). Examining the effects of home literacy and numeracy environment on early reading and math acquisition. Early Childhood Research Quarterly, 28, 692-703. http://dx.doi.org/10.1016/j. ecresq.2013.04.004

Mashburn, A. J., Pianta, R. C., Hamre, B. K., Downer, J. T., Barbarin, O., Bryant, D., et al. (2008). Measures of classroom quality in prekindergarten and children's development of academic, language, and social skills. Child Development, 79 , 732-749. http://dx.doi.org/10.1111/j.1467-8624.2008.01154.x

McAdoo, H. (2002). African American parenting. In M. Bornstein (Ed.), Handbook of parenting 4 (pp. 47-58). Mahwah, NJ: Lawrence Erlbaum Associates.

Mol, S., Bus, A., de Jong, M., \& Smeets, D. (2008). Added value of dialogic parent-child book readings: A meta-analysis. Early Education \& Development, 19, 7-28. http://dx.doi.org/10.1080/10409280701838603

Morrison, F., Bachman, H., \& Connor, C. (2008). Improving literacy in America: Guidelines from research. New Haven, CT: Yale University Press.

Morrison, F., \& Cooney, R. (2001). Parenting and academic achievement: Multiple paths to early literacy. In M. Bristol-Power (Ed.), Parenting and the child's world: Influences on academic, intellectual, and socio-emotional development (pp. 141-160). Mahwah, NJ: Lawrence Erlbaum Associates.

Ng, M., Guthrie, J., Van Meter, P., McCann, A., \& Alao, S. (1998). How do classroom characteristics influence intrinsic motivation for literacy? Reading Psychology, 19, 319-398. http://dx.doi.org/10.1080/0270271980190401

Ng, F., Kenney-Benson, G. A., \& Pomerantz, E. M. (2004). Children's achievement moderates the effects of mothers' use of control and autonomy support. Child Development, 75, 764-780. http://dx.doi.org/10.1111/j.1467-8624.2004.00705.

Olson, S. L., Bates, J. E., \& Kaskie, B. (1992). Caregiver-infant interaction antecedents of children's school-age cognitive ability. Merrill-Palmer Quarterly, 38, 309-330. http://www.jstor.org/stable/23087258

Pomerantz, E. M., \& Eaton, M. M. (2001). Maternal intrusive support in the academic context: Transactional socialization processes. Developmental Psychology, 37, 174-186. http://dx.doi.org/10.1037/0012-1649.37.2.174

Ramani, G., Rowe, M., Eason, S., \& Leech, K. (2015). Math talk during informal learning activities in Head Start families. Cognitive Development, 35, 15-33. http://dx.doi.org/10.1016/j.cogdev.2014.11.002

Reese, E., Sparks, A., \& Leyva, D. (2010). A review of parent interventions for preschool children's language and emergent literacy. Journal of Early Childhood Literacy, 10, 97-117. http://dx.doi.org/10.1177/1468798409356987

Rogoff, B. (2003). The cultural nature of human development. New York: Oxford University Press.

Saxe, G. B., Guberman, S. R., \& Gearhart, M. (1987). Social processes in early number development. Monographs of the Society for Research in Child Development, 52, 162. http://dx.doi.org/10.2307/1166071

Sénéchal, M., LeFevre, J., Thomas, E. H., \& Daley, K. E. (1998). Differential effects of home literacy experiences on the development of oral and written language. Reading Research Quarterly, 33, 96-116. http://dx.doi.org/10.1598/RRQ.33.1.5

Sénéchal, M., LeFevre, J. A., Smith-Chant, B. L., \& Colton, K. V. (2001). On refining theoretical models of emergent literacy the role of empirical evidence. Journal of School Psychology, 39, 439-460. http://dx.doi.org/10.1016/S00224405(01)00081-4

Sénéchal, M. \& LeFevre,J. (2002). Parental involvement in the development of children's reading skill: A five-year longitudinal study. Child Development, 73, 445-460. http://dx.doi.org/10.1111/1467-8624.00417

Siegler, R. S., Thompson, C. A., \& Schneider, M. (2011). An integrated theory of whole number and fractions development. Cognitive Psychology, 62, 273-296. http://dx.doi.org/10.1016/j.cogpsych.2011.03.001

Skibbe, L., Bindman, S., Hindman, A., Aram, D., \& Morrison, F. (2013). Longitudinal relations between parental writing support and preschoolers' language and literacy skills. Reading Research Quarterly, 48, 387-401. http://dx.doi.org/10. $1002 /$ rrq. 55

Skwarchuk, S. (2009). How do parents support preschoolers' numeracy learning experiences at home? Early Childhood Education Journal, 37, 189-197. http:// dx.doi.org/10.1007/s10643-009-0340-1

Spagnola, M., \& Fiese, B. (2007). Family routines and rituals: A context for development in the lives of young children. Young Children, 20, 284-299. http://dx.doi.org/10.1097/01.IYC.0000290352.32170.5a

Song, M., \& Ginsburg, H. (1987). The development of informal and formal mathematical thinking in Korean and U. S. children. Child Development, 58, 1286-1296 [doi?]

Teale, W., \& Sulzby, E. (1986). Emergent literacy: Writing and reading. Norwood, NJ: Ablex Publishing Corporation.

Thomas, H., \& Irwin, J. (2011). Cook It Up! A community-based cooking program for at-risk youth: Overview of a food literacy intervention. BioMedCentral (BMC) Research Notes, 4, 495-501. Retrieved from:. http://www.biomedcentral. com/1756-0500/4/495

Tolchinsky, L. (2003). The cradle of culture and what children know about writing and numbers before being taught. Mahwah, NJ: Lawrence Erlbaum Associates Publishers.

U.S. Census Bureau (2015). A Comparison of official poverty estimates in the redesigned current population Survey Annual Social and Economic Supplement. Prepared by J. Mitchell \& T. Renwick. SEHSD Working Paper \#2014-35. Retrieved from: www.census.gov/content/dam/Census/lirbrary/ working-papers/2014/demo/SEHSD-WP 2014-35.pdf. 
U.S. Department of Education, National Center for Education Statistics (2015). National Assessment of Educational Progress. Mathematics and Reading Progress at Grades 4 and 8. Retrieved from: http://www.nationsreportcard. gov/reading_math_2015/\#mathematics/gaps?grade=4.

Vandermaas-Peeler, M., Ferretti, L., \& Loving, S. (2012). Playing the ladybug game: Parent guidance of young children's numeracy activities. Early Child Development and Care, 182, 1289-1307. http://dx.doi.org/10.1080/03004430. 2011.609617

Vandermaas-Peeler, M., \& Pittard, C. (2014). Influences of social context on parent guidance and low-income preschoolers' independent and guided math performance. Early Child Development and Care, 184, 500-521. http://dx.doi. org/10.1080/03004430.2013.799155

Vygotsky, L. (1978). Mind in society: The development of higher mental functions. Cambridge, MA: Harvard University Press.

Weiland, C., Ulvestad, K., Sachs, J., \& Yoshikawa, H. (2013). Associations between classroom quality and children's vocabulary and executive function skills in an urban public prekindergarten program. Early Childhood Research Quarterly, 28 , 199-209. http://dx.doi.org/10.1016/j.ecresq.2012.12.002
Whiteside-Mansell, L., Bradley, R. H., Owen, M. T., Randolph, S. M., \& Cauce, A. M. (2003). Parenting and children's behavior at 36 months: Equivalence between African American and European American mother-child dyads. Parenting: Science and Practice, 3, 197-234. http://dx.doi.org/10.1207/ S15327922PAR0303_02

Woodcock, R., McGrew, K., \& Mather, N. (2001). Woodcock-Johnson tests of achievement. Itasca, IL: Riverside Publishing.

Yoshikawa, H., Aber, J., \& Beardslee, W. (2012). The effects of poverty on the mental, emotional, and behavioral health of children and youth: Implications for prevention. American Psychologist, 67, 272-284. http://dx.doi.org/10.1037/ a0028015 